\title{
Single Molecule Study of Cellulase Hydrolysis of Crystalline Cellulose
}

Conference Paper NREL/CP-270-47301

December 2009

\section{Preprint}

Y.-S. Liu, Y. Luo, J.O. Baker, Y. Zeng,

M.E. Himmel, and S.-Y. Ding

National Renewable Energy Laboratory

S. Smith

South Dakota School of Mines and Technology

To be presented at the Society of Photo-Optical Instrumentation Engineers (SPIE) Photonics West 2010

San Francisco, California

23-28 January 2010 


\section{NOTICE}

The submitted manuscript has been offered by an employee of the Alliance for Sustainable Energy, LLC (ASE), a contractor of the US Government under Contract No. DE-AC36-08-GO28308. Accordingly, the US Government and ASE retain a nonexclusive royalty-free license to publish or reproduce the published form of this contribution, or allow others to do so, for US Government purposes.

This report was prepared as an account of work sponsored by an agency of the United States government. Neither the United States government nor any agency thereof, nor any of their employees, makes any warranty, express or implied, or assumes any legal liability or responsibility for the accuracy, completeness, or usefulness of any information, apparatus, product, or process disclosed, or represents that its use would not infringe privately owned rights. Reference herein to any specific commercial product, process, or service by trade name, trademark, manufacturer, or otherwise does not necessarily constitute or imply its endorsement, recommendation, or favoring by the United States government or any agency thereof. The views and opinions of authors expressed herein do not necessarily state or reflect those of the United States government or any agency thereof.

Available electronically at http://www.osti.gov/bridge

Available for a processing fee to U.S. Department of Energy and its contractors, in paper, from:

U.S. Department of Energy

Office of Scientific and Technical Information

P.O. Box 62

Oak Ridge, TN 37831-0062

phone: 865.576.8401

fax: 865.576 .5728

email: mailto:reports@adonis.osti.gov

Available for sale to the public, in paper, from:

U.S. Department of Commerce

National Technical Information Service

5285 Port Royal Road

Springfield, VA 22161

phone: 800.553.6847

fax: 703.605.6900

email: orders@ntis.fedworld.gov

online ordering: http://www.ntis.gov/ordering.htm 


\title{
A single molecule study of cellulase hydrolysis of crystalline cellulose
}

\author{
Yu-San Liu ${ }^{\mathrm{a}, \mathrm{b}}$, Yonghua Luo ${ }^{\mathrm{a}}$, John O. Baker ${ }^{\mathrm{a}}$, Yining Zeng ${ }^{\mathrm{a}, \mathrm{b}}$, Michael E. Himmel ${ }^{\mathrm{a}, \mathrm{b}}$, Steve Smith ${ }^{\mathrm{c}}$, \\ Shi-You Ding ${ }^{\mathrm{a}, \mathrm{b}}$ * \\ ${ }^{\mathrm{a}}$ Chemical and Biosciences Center, National Renewable Energy Laboratory, Golden, CO 80401; \\ ${ }^{\mathrm{b}}$ Bioenergy Science Center, Oak Ridge National Laboratory, Oak Ridge, TN 37830; \\ ${ }^{c}$ Nanoscience and Nanoengineering, South Dakota School of Mines \& Technology, Rapid City, SD
}

57701

\begin{abstract}
Cellobiohydrolase-I (CBH I), a processive exoglucanase secreted by Trichoderma reesei, is one of the key enzyme components in a commercial cellulase mixture currently used for processing biomass to biofuels. CBH I contains a family 7 glycoside hydrolase catalytic module, a family 1 carbohydrate-binding module (CBM), and a highlyglycosylated linker peptide. It has been proposed that the CBH I cellulase initiates the hydrolysis from the reducing end of one cellulose chain and successively cleaves alternate $\beta-1,4$-glycosidic bonds to release cellobiose as its principal end product. The role each module of CBH I plays in the processive hydrolysis of crystalline cellulose has yet to be convincingly elucidated. In this report, we use a single-molecule approach that combines optical (Total Internal Reflection Fluorescence microscopy, or TIRF-M) and non-optical (Atomic Force Microscopy, or AFM) imaging techniques to analyze the molecular motion of CBM tagged with green fluorescence protein (GFP), and to investigate the surface structure of crystalline cellulose and changes made in the structure by CBM and CBH I. The preliminary results have revealed a confined nanometer-scale movement of the $\operatorname{Tr}$ CBM1-GFP bound to cellulose, and decreases in cellulose crystal size as well as increases in surface roughness during CBH I hydrolysis of crystalline cellulose.
\end{abstract}

Keywords: Single molecule spectroscopy, AFM, TIRF, cellulose, carbohydrate-binding module (CBM), Cellobiohydrolase (CBH I)

\section{INTRODUCTION}

Biofuels derived from lignocellulosic plant biomass are an attractive alternative to current petroleum-based fuels, due to their potential for sustainability as well as reduction of greenhouse gas emissions. The feedstock used for biofuel production is primarily plant cell wall materials from crop residues, short rotation transgenic trees (e.g., poplars), woody grasses (e.g., switchgrass), forestry waste, construction waste, waste from pulp and paper production, agricultural residues and municipal solid waste. Current technology uses a combined chemical and biological process to convert plant biomass to biofuels, which process involves (i) a thermochemical pretreatment step to alter the plant cell wall structure to be amenable to enzymatic attack; (ii) an enzymatic saccharification step to produce simple sugars; and (iii) production of liquid fuels in a fermentation step. For this overall process, the cost of cellulose-degrading enzymes remains a major cost. Whatever the specific biomass conversion scheme eventually employed in industrial biofuels plants, the catalytic efficiency of the glycoside hydrolases utilized must be near theoretical values if the process is to be cost effective and robust. This consideration is especially true of the cellulases. However, little direct information is available concerning the actions of cellulases as catalysts in hydrolysis of the complex plant cell wall materials, largely due to the lack of techniques that are suitable for characterizing the complex system of plant cell walls and the enzymes that deconstruct them. To this end, we focus on developing imaging techniques combining optical and non-optical microscopy to elucidate the enzymatic processes of the plant cell wall at the molecular scale. In this context, we report a preliminary study in which the interactions of cellulase components with crystalline cellulose are tracked by means of single-molecule approaches using Total Internal Reflection Fluorescence (TIRF) microscopy and Atomic Force Microscopy (AFM).

Cellulose is a linear polysaccharide composed of $\beta$-1,4-linked anhydroglucose residues, and is the major sugar source to be considered in lignocellulosic biofuel production, in that it accounts for $40 \%-60 \%$ by weight of plant biomass. In 
native plant cell walls, cellulose exists at nanometer scale as a microfibril network embedded in matrices of hemicelluloses, pectins and lignins. Synergistic reaction of various enzymes is required to efficiently break down this chemically and physically complex plant cell wall polymeric network. These enzymes include cellulases, hemicellulases and accessory enzymes, and catalysts that modify lignins. The cellulases are a class of enzymes produced mainly by fungi and bacteria. These enzymes catalyze hydrolysis of the $\beta$-1,4-glucosidic bonds that link the glucosyl units of cellulose, and have been classified on the basis of their modes of action on the substrate into three distinct classes of enzymes that react synergistically: (i) the endo- $\beta-(1,4)$-glucanases that cleave the cellulose chain at internal positions to produce ends ${ }^{1}$, (ii) the exo- $\beta-(1,4)$-D-glucanases that cleave from the ends of cellulose chains to produce cellobiose, and (iii) the $\beta$-D-glucosidases that hydrolyze cellobiose to glucose. Two protein modules are usually involved in the enzymatic function, a catalytic module that catalyze the hydrolysis, and a carbohydrate-binding module (CBM) that provides recognition of, and binding to the substrate. Understanding at a molecular level how cellulose is hydrolyzed by cellulase can provide rationales for engineering more effective enzymes for biomass conversion. Over the last decade, researchers have investigated cellulose-cellulase interaction through a combination of biochemical methods and imaging techniques, such as fluorescence microscopy ${ }^{2,3}$ and transmission electron microscopy (TEM) ${ }^{4}$. It remains challenging to study cellulase interaction with insoluble cellulose substrate and the kinetics of the catalyzed hydrolysis using these traditional approaches. Recently, we have employed single-molecule spectroscopy (SMS) to measure the dynamics of individual cellulases and cellulose, and have observed linear motion of a bacterial CBM along the cellulose axis of a cellulose crystal ${ }^{5}$.

SMS can be achieved by both optical and non-optical approaches. For example, TIRF-M is an optical method that uses the evanescent wave generated by the light totally internally reflected at the interface between a transparent solid (e.g., coverglass) and liquid media to excite fluorescent molecules in the liquid just beyond the interface. Since the intensity of the evanescent wave exponentially decays with distance from the surface of the coverglass, only fluorescent molecules within a few hundred nanometers of the solid are efficiently excited. SMS data therefore can be acquired using trajectory tracking of fluorescently-labeled molecules. AFM is a non-optical (mechanical) method that offers a topological description of the substrate surface at atomic resolution. We have demonstrated that AFM is a powerful analytical tool that can be used to obtain highly accurate images of cellulose ${ }^{6}$ and plant cell wall ${ }^{7}$ surfaces under physiological conditions with nanometer resolution. Here we report the study of the morphological structure of Valonia crystalline cellulose and changes induced in the crystals by Trichoderma reesei cellobiohydrolase I (CBH I) cellulase and/or CBM using both AFM and TIRF-M.

*shi.you.ding@nrel.gov; phone 1303 384-7758; fax 1303 384-7752

\section{MATERIALS AND METHODS}

\subsection{Preparation of cellulose, $T$, reesei $\mathrm{CBH}$ I and $\operatorname{TrCBM1-GFP}$}

The cellulose crystals used for this study were isolated from the green alga, Valonia ventricosa ${ }^{8}$. Purified Valonia cellulose crystals were dispersed in water. A single cellulose crystal is approximately $20-40 \mathrm{~nm}$ in diameter and several micrometers in length.

The CBH I from T. reesei contains a family-7 glycoside hydrolase (GH7) and a family-1 CBM, connected by a highly glycosylated linker segment. The sequence-deduced molecular weight of the CBH I peptide chain is approximately $52,208 \mathrm{Da}$, and the native CBH I with glycosylation usually exhibits an apparent molecular weight near $60 \mathrm{kDa}$ in SDSPAGE. CBH I used in this study was purified from a seven-day broth of T. reesei grown on Sigmacell (Sigma-Aldrich Corporation, St. Louis MO, USA) as carbon source. The detailed protocol has been described elsewhere ${ }^{9}$.

The $\operatorname{TrCBM} 1$ is a family $1 \mathrm{CBM}$ taken from the CBH I gene of $T$. reesei. It was synthesized (GenScript Company, Piscataway, NJ) with genetic code optimization for expression in E. coli. The gene also includes a sequence encoding an $N$-terminal 6xHis tag. The synthesized DNA fragment was amplified using the polymerase chain reaction (PCR) with primers 5'-GATATAGCATGCCCATCATC-3' and 5'-AGTTCTACCGGTACCAGGCACTGGC-3', and cloned into 
pGFPuv (Clontech, Mountain View, CA) using restriction enzymes SphI and AgeI to generate expression plasmid p $\operatorname{TrCBM1-GFP~that~contains~} \operatorname{TrCBM} 1$ tagged with green fluorescent protein (GFP). It was then over-expressed in $E$. coli strain of BL21 (DE3) (Stratagene, La Jolla, CA). The resulting fusion proteins were purified using the QIAexpress Ni-NTA protein purification system (Qiagen, Valencia, CA). The deduced molecular weight of $\operatorname{TrCBM1-GFP~is~33,140}$ Da. The recombinant $\operatorname{TrCBM}$-GFP concentration was measured by NanoDrop 1000 (Thermo Scientific, Wilmington, DE, USA) and subsequently diluted with Tris buffer (50 mM Tris, $\mathrm{pH} 8.0)$ to optimize the resolution for single molecule detection. The purified protein was stored at $4^{\circ} \mathrm{C}$ at a final concentration of $1 \mathrm{mg} / \mathrm{mL}$ in $20 \mathrm{mM}$ Tris buffer (pH 8.0) containing $0.01 \%(\mathrm{w} / \mathrm{v}) \mathrm{NaN}_{3}$.

\subsection{Atomic force microscopy (AFM) measurement}

Freshly cleaved mica coated with an amine polymer, polylysine, was used to generate a flat, smooth, and stationary substrate and immobilize the celluloses firmly to overcome the forces applied by the AFM probe and to permit resolution of the sample. In the experiment, $5-\mu \mathrm{L}$ of poly-DL-lysine hydrobromide $(4-15 \mathrm{KDa}, 1 \mathrm{mg} / \mathrm{mL}$ in water) (Sigma-Aldrich, St. Louis, MO) was added to freshly cleaved mica. After 5 minute incubation, the excess solution was removed by a spin coater $(500 \mathrm{rpm}$ for $30 \mathrm{sec}$ followed by $4000 \mathrm{rpm}$ for $30 \mathrm{sec}$ ) (KW-4A, Chemat Technology, Northridge, CA). After that, $5 \mu \mathrm{L}$ of a suspension of cellulose crystals $(1 \mathrm{mg} / \mathrm{mL}$ in water) was added, followed by incubation and spin coating as in the above procedure. The coated mica was then dried in an oven at gentle heat $(45 \mathrm{C})$ overnight. AFM was operated in tapping mode in fluid. We found that $150-\mu \mathrm{L}$ liquid droplet formed on cellulose-coated mica was sufficient for imaging for at least 10 hours without significant artifact caused by water evaporation. Acetate buffer (20 mM acetate, $\left.0.2 \% \mathrm{NaN}_{3}, 100 \mathrm{mM} \mathrm{NaCl}, \mathrm{pH} 5.0\right)$ was used for buffer-control imaging, and the same buffer was also used for imaging treatments of CBH I $(1 \mathrm{mg} / \mathrm{mL})$ or $\operatorname{Tr}$ CBM1-GFP $(0.78 \mathrm{mg} / \mathrm{mL})$ on cellulose. A Multi-Mode ${ }^{\mathrm{TM}}$ scanning probe microscope (SPM) with NanoScope V controller (Veeco, Santa Barbara, California) was used for AFM measurements. To ensure absolute stability, the AFM was located in a specially designed laboratory with acoustic and vibration isolation. A customized Nikon optical microscope with deep focus (800X magnification) was used to aid the positioning of the AFM tip to the desired location. Silicon nitride probes (NP) and sharp nitride lever (SNL) probes (Veeco, Santa Barbara, California) were used in tapping mode to image cellulose fibers in liquid. Images of cross section and roughness were analyzed using Nanoscope 7.30 software. Surface roughness was evaluated by flattening the images (second-order) and calculation of Ra and Rq.

\subsection{TIRF-M observation and trajectory tracking}

$1 \mu \mathrm{g}$ of $\operatorname{Tr}$ CBM1-GFP protein in solution was incubated with $25 \mu \mathrm{g}$ of Valonia cellulose crystals in $200 \mu \mathrm{L}$ of Tris buffer ( $50 \mathrm{mM}$ Tris, $\mathrm{pH} 8.0$ ) with gentle mixing for 10 minutes, followed by centrifugation (10,000 x g for $5 \mathrm{~min})$. The protein-bound cellulose pellets were washed three times to remove unbound $\operatorname{Tr}$ CBM1-GFP present in the solution. The resulting $\operatorname{Tr}$ CBM-GFP bound cellulose complexes were suspended in $50 \mu \mathrm{L}$ of Tris buffer for single molecule detection. Freshly prepared samples $(2-\mu \mathrm{L}$ volume $)$ were placed between two glass coverslips. After the sample spread out by capillary effect, the cover slips were pressed together hard to minimize optical depth of the sample and to obtain a thin and even distribution of cellulose substrate fibers, maintained in an aqueous environment.

TIRF microscopy (TIRF-M) was performed on an Olympus IX71 inverted microscope equipped with a QuantEM: 512SC (Roper Scientific, Trenton, NJ, USA) camera. A $488 \mathrm{~nm}$ argon laser (Melles Griot, Albuquerque, NM, USA) was used as the excitation source. Excitation and emission filters were, respectively, 488/10X nm and 525/50M nm. A notch filter (488-S3D, Omega, Stamford, Connecticut, USA) was also placed before the camera to further suppress noise. A 150X lens (UApo, oil immersion and N.A. $=1.45$ ) was used for these observations. TIRF images were recorded as a sequence for later tracking analysis. Each sequence of images was analyzed by DIATRACK software (Semasopht, North Epping, Australia). All the spots on an image in the sequence were analyzed. Each spot, which in most cases represents one single molecule, was fitted with a two-dimensional Gaussian function ${ }^{10}$. The centroid of a spot in one image was determined as the peak of the fitting Gaussian function. The centroids of the same spot throughout the sequence of images were determined from one frame to the next and finally reconstructed as a spatial trajectory recording the movement of the spot. 


\section{RESULTS AND DISCUSSIONS}

\section{1 $\operatorname{TrCBM1-GFP~on~cellulose~crystals~}$}

CBMs are non-catalytic protein modules found in many glycoside hydrolase enzymes, such as cellulases and hemicellulases. CBMs have the function of recognizing and targeting the specific sites to convey the catalytic modules of these enzymes to target substrates, such as cellulose or hemicelluloses. Surface absorption of CBM to insoluble polysaccharide substrates is a critical step in the catalytic activities of plant cell wall degrading enzymes. Studying how CBM behaves on cellulose is essential for understanding the cellulase enzyme action. In this study, a family-1 CBM ( $\operatorname{Tr}$ CBM1) is derived from a typical exo-glucanase, $T$. reesei CBHI. Note that this type of CBM is solely produced by fungi as parts of glycoside hydrolases, and it is thought to play an important role in the processive action of CBH I to hydrolyze crystalline cellulose.

AFM amplitude images were captured in buffer (Figure 1A, and 1B after 4 hours) and in $\operatorname{TrCBM1-GFP}$ solution (Figure 1C, and 1D after 4-hour treatment) on the same cellulose crystal. The cellulose fibers exhibited little or no change in size but fine features on surface (denoted by the white arrow) disappeared as measured after buffer and $\operatorname{TrCBM1-GFP}$ treatment. This apparent change of cellulose surface may be attributed to the disruption of the surface by CBM binding and diffusion. Further experiments are needed to verify the generality of such effects by employing $\operatorname{Tr}$ CBM1-GFP fusion proteins constructed by using different CBMs from other glycoside hydrolases.

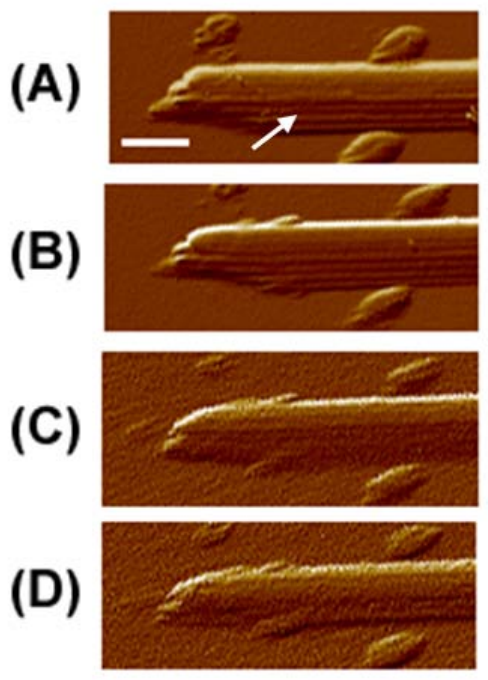

Figure 1. AFM amplitude images of Valonia cellulose. Images were taken after (A) $0 \mathrm{hr}$ and (B) 4 hours in buffer, and after exposure to $\operatorname{Tr}$ CBM1-GFP solution for (C) $0 \mathrm{hr}$ and (D) 4 hours. No obvious changes in the cellulose size were observed, but fine features of cellulose surface were missing after TrCBM1-GFP treatment. The scale bar represents $250 \mathrm{~nm}$.

We have previously reported that CBM indeed exhibits linear motion along the cellulose axis of cellulose crystal $^{5}$. Both the CBM used in this study ( $\operatorname{Tr} \mathrm{CBM} 1$ from fungus $T$. reesei) and that used in the previous report (AcCBM2 from bacterium Acidothermus cellulolyticus) are categorized as surface-binding CBMs; it has been confirmed that this type of CBM binds specifically to the planar faces of cellulose ${ }^{5,6}$. To further demonstrate whether the $\operatorname{TrCBM1-GFP}$ exhibits similar motion on cellulose, we employed the same TIRF-M instrumentation as previous reported to analyze the molecular motion of $\operatorname{TrCBM} 1-\mathrm{GFP}$ bound cellulose crystals. Figure2 shows the imaging and tracking results of $\operatorname{TrCBM1-GFP.~An~area~of~interested~was~selected~in~white~light~microscopy~(Figure~2A)~to~contain~well-dispersed~}$ cellulose crystals. TIRF-M imaging (Figure 2B) was taken in the same area using a GFP-specific filter set. TIRF signals (white sports) are overlap perfectly with the cellulose fibers, which confirms that $\operatorname{TrCBM1-GFP}$ molecules bind to cellulose specifically. Figure $2 \mathrm{C}$ shows one cellulose fiber containing five single $\operatorname{TrCBM}$ 1-GFP molecules lined up on the cellulose. The fluorescence intensity of GFP vs time exhibits single step photobleaching, indicating that the observed fluorescent spot (yellow circled) is a single GFP (Figure 2D). By tracking this single GFP, we observed that the $\operatorname{Tr} \mathrm{CBM} 1$ exhibited linear motion along the long axis of the cellulose fiber (Figure 2E) similar to that reported previously for $A c \mathrm{CBM} 2$. 
(A)

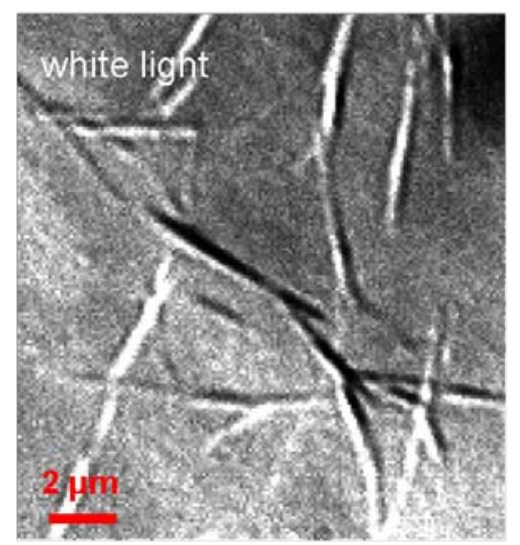

(B)

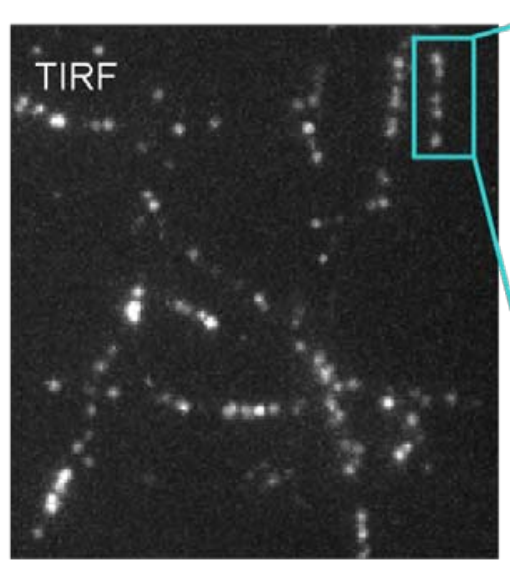

(E)

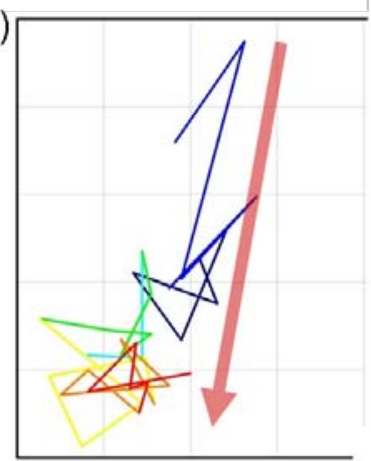

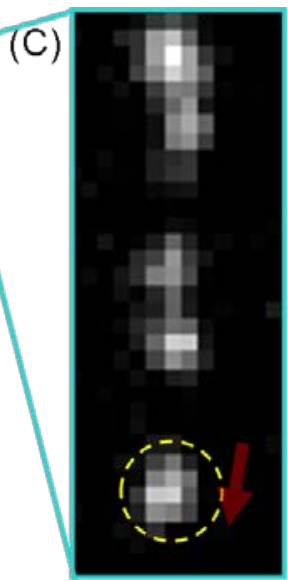

Time (s)

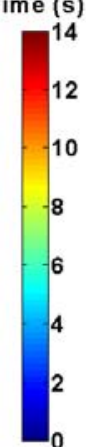

Figure 2. Single-molecule tracking of $\operatorname{Tr}$ CBM1-GFP. (Top) White-light (A) and TIRF images (B) of cellulose crystals labeled by $\operatorname{Tr}$ CBM1-GFP were captured in the same area. The yellow circled spot on one cellulose fiber lined up with one of 5 apparent single molecules (blue box in B and C) and was selected for single molecule analysis. The scale bar represents $2 \mu \mathrm{m}$. The fluorescence intensity vs time plot shows single step photobleaching (D), and the trajectory demonstrates $\operatorname{Tr}$ CBM1-GFP moving along the axis of the cellulose crystal (E, red arrow). The color coded bar represents the time scale of $14 \mathrm{sec}$.

\subsection{Cellulose surface affected by CBH I}

The enzyme mixture used in the current process of biomass conversion (the enzymatic saccharification step) is primarily derived from the fungal enzyme system secreted by T. reesei. CBH I accounts for more than $60 \%$ of the total secreted protein ${ }^{11}$. It is believed that $\mathrm{CBH}$ I is an exoglucanase that is an essential component in the fungal free enzyme system required for the efficient hydrolysis of crystalline cellulose in plant cell wall biomass. A mechanism for the action of CBH I on crystalline cellulose has been proposed - the surface-binding family $1 \mathrm{CBM}$ approaches and binds to the planar surface of cellulose, and one cellulose chain is threaded into an active-site tunnel in family 7 catalytic module, and the active-site residues in the tunnel then "processively" catalyze the hydrolysis of every other one of the $\beta-1,4-$ glucosidic bonds linking the individual glucose units to produce cellobiose, this last proposed feature being based primarily on the analytical finding that $\mathrm{CBH}$ I produces mainly cellobiose. A recent study based in fast-AFM of CBH I on cellulose crystal seems supportive of this proposed mechanism ${ }^{12}$. In this study, we used AFM to image cellulose crystals continuously during exposure to native T. reesei $\mathrm{CBH}$ I in acetate buffer. The objective was to learn how the enzyme affects the cellulose morphology. Figure 3A and 3B show AFM height images of cellulose exposed to CBH I for 4 and 10 hours, respectively. With the same scanning size and area, we observed that cellulose size significantly decreases over a 6-hour treatment by CBH I. Apparently, the cellulose size reduction is indeed the result of CBH I hydrolysis. 

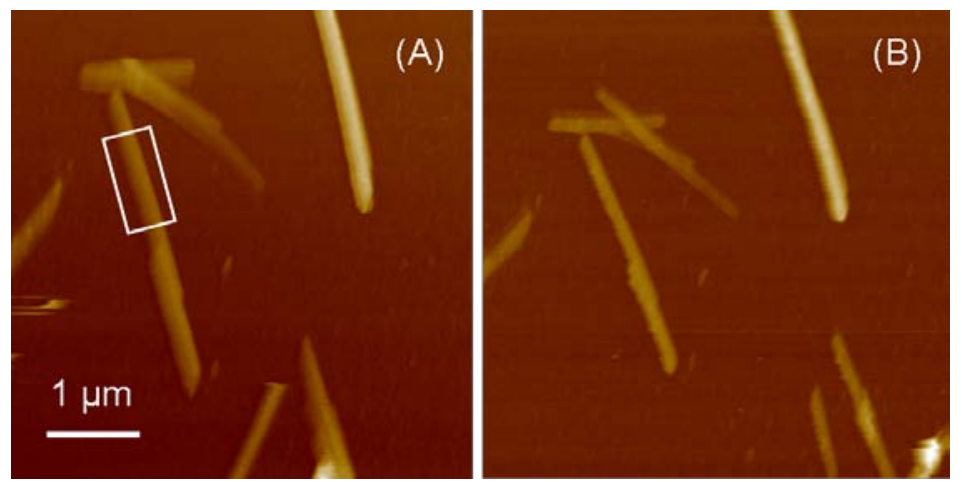

Figure 3. AFM height images of Valonia cellulose acquired in acetate buffer after CBH I treatment for 4 (A) and 10 hours (B). Apparent cellulose size decreases significantly during the 6-hour observation. Scale bar represents 1 $\mu \mathrm{m}$.

The CBH I-induced changes in cellulose-crystal morphology were assessed quantitatively by analysis of a series of AFM images captured during CBH I treatment. The observed area contained one cellulose crystal crossed by about 50 cross section lines (based on 512 × 512 scan lines); the profiles of the average cross sections of these 50 lines are shown in Figure 4, at two different times during the CBH I treatment. Between 4- and 10-hours CBH I treatment, the average width of the cellulose crystal decreases, but the average height remains the same. The apparent shrinking of cellulose width implies that the CBH I tends to hydrolyze cellulose from certain surfaces, which is consistent with the observation of CBMs binding only to certain faces of cellulose crystal. A further hypothesis remaining to be verified experimentally is that it is specifically only the planar faces of cellulose on which CBH I acts. By integrating the area under the curves, we have calculated the area of cellulose cross section which is proportional to cellulose size. We find that the size decreases by $7.5 \%$ in CBH I-treated cellulose between 4 and 10 hours. Note that the observed $7.5 \%$ size change is obtained based on the analysis of AFM images and is thus not the actual cellulose size change due to the AFM tip shape and broadening artifacts.

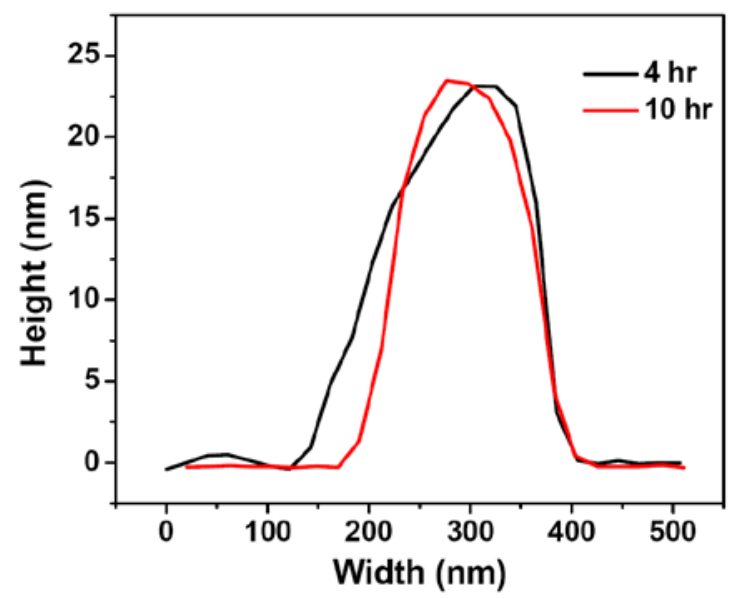

Figure 4. Cellulose width decreases in the CBH I solution after 10 hours whereas height remains the same. Black and red line represent 4 and 10 hours after adding $\mathrm{CBH}$ I, respectively.

AFM is capable of measuring the surface structure at atomic resolution, and we further analyzed the structural changes of cellulose surface that are affected by the CBM or the CBH I. One of the features of AFM measurement is the degree of roughness that could be used to analyze the surface affected by friction, adhesion, and catalytic activity. There are many mathematical approaches to calculate surface roughness from AFM images, including probability height distributions, fractal analysis, mean roughness ( $\mathrm{Ra}$ ), and root mean squared roughness (Rq). Ra and Rq are most commonly reported measures of surface roughness from AFM images. Figure 1 shows the changes of fine features on the cellulose surface that apparently resulted from the $\operatorname{Tr} \mathrm{CBM} 1$ binding. Figure 5 represents roughness measurement of the cellulose fiber shown in the white box of Figure 3. We find that cellulose surface roughness increases (in both Ra and Rq cases) by 1-2 $\mathrm{nm}$ after $\mathrm{CBH}$ I treatment, which further confirmed that the apparent morphological changes of 
cellulose observed by AFM are the results of CBH I treatment. It may also imply that the hydrogen bond network of the surface chains of cellulose is altered by the process of CBM binding and CBH I hydrolysis.

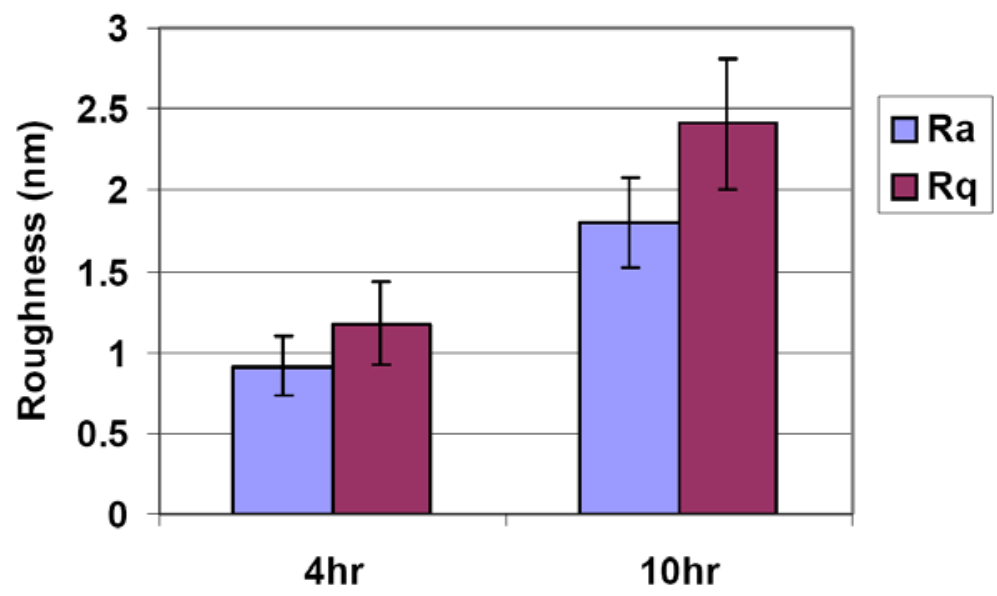

Figure 5. Cellulose surface roughness increases after $\mathrm{CBH}$ I treatment. Blue and purple bars represent Ra and Rq at 4 (Figure 3A) and 10 hours (Figure 3B), respectively, after adding CBH I. Ra stands for mean roughness and Rq stands for root mean squared roughness.

\section{CONCLUSIONS}

Single molecule approaches based on optical (TIRF) and non-optical (AFM) techniques were applied to measure effects of cellulase attack on the morphology of crystalline cellulose. We demonstrated that the structural changes of cellulose, i.e., decreases of width and increases of surface roughness, which were affected by $T$. reesei CBH I could be imaged in real-time in solution; and that the linear and directional motion of single GFP-tagged $\operatorname{TrCBM1}$ could be observed.

\section{ACKNOWLEDGEMENTS}

The authors gratefully acknowledge the U.S. Department of Energy, Office of Energy Efficiency and Renewable Energy Biomass Program for support of the work to develop carbohydrate module proteins and enzymes, and support from the DOE Office of Science, Office of Biological and Environmental Research through the BioEnergy Science Center (BESC), a DOE Bioenergy Research Center, for the work on single molecule visualization and analysis.

\section{REFERENCES}

[1] Reese E.T., S.R.G.H., Levinson H.S., "The biological degradation of soluble cellulose derivatives and its relationship to the mechanism of cellulose hydrolysis," J. Bacteriol. 59, 485-497 (1950).

[2] Moran-Mirabal, J.N., Santhanam, N., Corgie, S.C., Craighead, H.G. and Walker, L.P., "Immobilization of Cellulose Fibrils on Solid Substrates for Cellulase-Binding Studies Through Quantitative Fluorescence Microscopy," Biotechnology and Bioengineering 101, 1129-1141 (2008).

[3] Helbert, W., Chanzy, H., Husum, T.L., Schulein, M. and Ernst, S., "Fluorescent cellulose microfibrils as substrate for the detection of cellulase activity," Biomacromolecules 4, 481-487 (2003).

[4] Boisset, C., Fraschini, C., Schulein, M., Henrissat, B. and Chanzy, H., "Imaging the enzymatic digestion of bacterial cellulose ribbons reveals the endo character of the cellobiohydrolase Cel6A from Humicola insolens and its mode of synergy with cellobiohydrolase Cel7A," Applied and Environmental Microbiology 66, 1444-1452 (2000).

[5] Liu, Y.S., Zeng, Y.N., Luo, Y.H., Xu, Q., Himmel, M.E., Smith, S.J. and Ding, S.Y., "Does the cellulose-binding module move on the cellulose surface?" Cellulose 16, 587-597 (2009). 
[6] Ding, S.Y., Xu, Q., Ali, M.K., Baker, J.O., Bayer, E.A., Barak, Y., Lamed, R., Sugiyama, J., Rumbles, G., Himmel, M.E., "Versatile derivatives of carbohydrate-binding modules for imaging of complex carbohydrates approaching the molecular level of resolution," Biotechniques 41, 435-443 (2006).

[7] Ding, S.Y. and Himmel, M.E., "The maize primary cell wall microfibril: A new model derived from direct visualization," Journal of Agricultural and Food Chemistry 54, 597-606 (2006).

[8] Imai, T., Putaux, J.L. and Sugiyama, J., "Geometric phase analysis of lattice images from algal cellulose microfibrils," Polymer 44, 1871-1879 (2003).

[9] Baker, J.O., Adney W.S., Thomas S.R., Nieves, R.A., Chou, Y.C., Vinzant, T.B., Tucker, M.P., Laymon, R.A., and Himmel, M.E., "Synergism between purified bacterial and fungal cellulases," ACS Symposium Series 618, 113-141 (1995).

[10] Thompson, R.E., Larson, D.R. and Webb, W.W., "Precise nanometer localization analysis for individual fluorescent probes," Biophysical Journal 82, 2775-2783 (2002).

[11] Enari, T.M., and Niku-Paavola, M.L., "Enzymatic hydrolysis of cellulose: Is the current theory of the mechanism of hydrolysis valid?" Critical Reviews in Biotechnology 5, 67-87 (1987).

[12] Igarashi, K., Koivula, A., Wada, M., Kimura, S., Penttila, M., and Samejima, M., " High-speed atomic force microscopy visualizes processive movement of Trichoderma reesei cellobiohydrolase I on crystalline cellulose," J. Biol. Chem. DOI 10.1074 (2009). 


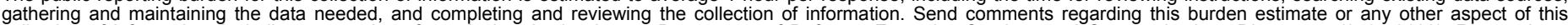

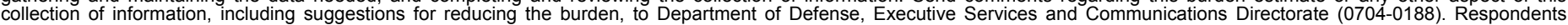

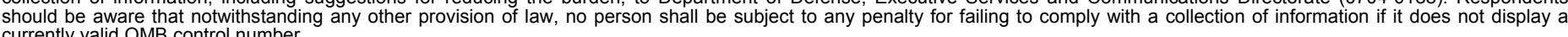

PLEASE DO NOT RETURN YOUR FORM TO THE ABOVE ORGANIZATION.

\begin{tabular}{l|l|l|} 
1. REPORT DATE $(D D-M M-Y Y Y Y)$ & 2. REPORT TYPE & 3. DATES COVERED (FrOm - TO)
\end{tabular}

December 2009

Conference Paper

4. TITLE AND SUBTITLE

Single Molecule Study of Cellulase Hydrolysis of Crystalline

Cellulose

5a. CONTRACT NUMBER

DE-AC36-08-GO28308

5b. GRANT NUMBER

5c. PROGRAM ELEMENT NUMBER

5d. PROJECT NUMBER

NREL/CP-270-47301

Y.-S. Liu, Y. Luo, J.O. Baker, Y. Zeng, M.E. Himmel, S. Smith, and S.-Y. Ding 5e. TASK NUMBER

BB072330

5f. WORK UNIT NUMBER
7. PERFORMING ORGANIZATION NAME(S) AND ADDRESS(ES)

National Renewable Energy Laboratory

1617 Cole Blvd.

Golden, CO 80401-3393

9. SPONSORING/MONITORING AGENCY NAME(S) AND ADDRESS(ES)
8. PERFORMING ORGANIZATION REPORT NUMBER

NREL/CP-270-47301

10. SPONSOR/MONITOR'S ACRONYM(S) NREL

11. SPONSORING/MONITORING AGENCY REPORT NUMBER

12. DISTRIBUTION AVAILABILITY STATEMENT

National Technical Information Service

U.S. Department of Commerce

5285 Port Royal Road

Springfield, VA 22161

13. SUPPLEMENTARY NOTES

14. ABSTRACT (Maximum 200 Words)

Cellobiohydrolase-I (CBH I), a processive exoglucanase secreted by Trichoderma reesei, is one of the key enzyme components in a commercial cellulase mixture currently used for processing biomass to biofuels. CBH I contains a family 7 glycoside hydrolase catalytic module, a family 1 carbohydrate-binding module (CBM), and a highlyglycosylated linker peptide. It has been proposed that the $\mathrm{CBH}$ I cellulase initiates the hydrolysis from the reducing

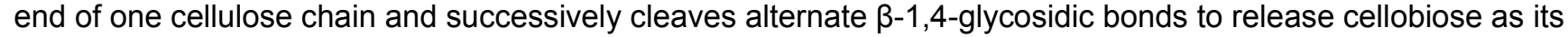
principal end product. The role each module of $\mathrm{CBH}$ I plays in the processive hydrolysis of crystalline cellulose has yet to be convincingly elucidated. In this report, we use a single-molecule approach that combines optical (total internal reflection fluorescence microscopy or TIRF-M) and non-optical (atomic force microscopy or AFM) imaging techniques to analyze the molecular motion of CBM tagged with green fluorescence protein (GFP) and to investigate the surface structure of crystalline cellulose and changes made in the structure by CBM and CBH I. Preliminary results reveal a confined nanometer-scale movement of the TrCBM1-GFP bound to cellulose, decreases in cellulose crystal size, and increases in surface roughness during $\mathrm{CBH}$ I hydrolysis of crystalline cellulose.

15. SUBJECT TERMS

single molecule spectroscopy;atomic force microscopy (AFM); total internal reflection fluorescence (TIRF);cellulose; carbohydrate-binding module (CBM); cellobiohydrolase-I ( $\mathrm{CBH} \mathrm{I})$;

\begin{tabular}{|c|c|c|c|c|}
\hline \multicolumn{3}{|c|}{ 16. SECURITY CLASSIFICATION OF: } & \multirow{2}{*}{$\begin{array}{l}\text { 17. LIMITATION } \\
\text { OF ABSTRACT } \\
\text { UL }\end{array}$} & \multirow{2}{*}{$\begin{array}{ll}\text { 18. } & \text { NUMBER } \\
\text { OF PAGES }\end{array}$} \\
\hline $\begin{array}{l}\text { a. REPORT } \\
\text { Unclassified }\end{array}$ & $\begin{array}{l}\text { b. ABSTRACT } \\
\text { Unclassified }\end{array}$ & $\begin{array}{l}\text { c. THIS PAGE } \\
\text { Unclassified }\end{array}$ & & \\
\hline
\end{tabular}

19a. NAME OF RESPONSIBLE PERSON

19b. TELEPHONE NUMBER (Include area code) 